are demands for universality. In the case of the middle term the demand is absolute. But, since universality and tenselessness and freed activity belong together, the familiar rule that the middle term must be distributed only shows that reasoning depends unconditionally upon activity. I would suggest, in order rather to give my general meaning than to say anything at all final, that the fallacy of the undistributed middle represents in projection an unmediated impulse, while the illicit processes of the major and the minor terms represent respectively action under coercion from environment and rash or random action.

But I must conclude. I have said here if $I$ have not shown (I) that environment in its entirety is the real medium of thought, (2) that judgment is, among other descriptions, the tension of adjustment, and (3) that formal logic as a body of doctrine is activity projected upon language. I recognize clearly enough that my ideal in this short paper has been better than the execution. If, however, only what I have wanted to do is now evident the labor has not been in vain. Nothing in philosophy is so much needed at the present time as the adjustment of the science of abstract thought to the science of organic action, and every little hint as to how that adjustment can be brought about cannot but be at least a little help. The evolution of consciousness must be almost meaningless until the simplest case of accommodation as seen by the biologist is identified with the most perfect case of abstract thought that the logician knows.

Alfred H. Lloyd.

UnIVERSITY OF Michigan.

\title{
COMMUNITY OF IDEAS OF MEN AND WOMEN.
}

Prof. Jastrow's criticism ${ }^{1}$ upon the methods, and therefore the results, of a Wellesley College study of the mental community of men and women ${ }^{2}$ has led me to repeat the experiment, following with extreme precision the lines which he has laid down. At the outset, I wish to acknowledge the justice of Dr. Jastrow's fundamental criticism upon the divergence of method. The earlier Wellesley experiment should indeed have conformed exactly with the methods of the experiment whose conclusions were questioned. For reasons which I shall later indicate, the divergencies were not considered 'essential,' and the results of the later experiment which I now report seem to me to confirm

'Psychological Review, January, 18g6. p. 68.

I Ibid. July, 1895, p. $3^{6} 3$. 
this view in some important features, though not in all. In this new test, lists of 100 words were written 'as rapidly as possible' by about fifty women students of Wellesley. Twenty-five of these lists were chosen entirely at random from among those written in the shortest time. The average time occupied was five minutes and one-sixth second, a somewhat shorter time than that reported by Dr. Jastrow (five minutes eight seconds); the lists are therefore free from any suspicion of being 'less natural and unreflective' than those which he studies. With the efficient aid of Miss Mary A. Dartt the words have been very carefully classified. I have guarded the entrance to every one of the twenty-five classes by a scrupulous consideration of each of the 2,500 words, and have even ventured to submit certain doubtful cases to Dr. Jastrow, to whom my thanks are due for his kind adjudication of their claims.

Before giving the results, I may remark, in reference to one of Dr. Jastrow's comments, that the reason for using only fifteen of the earlier lists, in the count of different words, is a mysterious loss of records. Making every allowance, however, for the increase in repetition with - the growing number of words, it is overwhelmingly probable that the ten last lists together contained 300 new words, a number more than sufficient to bring them up to the total of the Wisconsin men's lists. Indeed, the ten cards last classified in the present experiment successively added more than thirty new words to the 'different words' already accumulated, and two of the very latest lists were among the most varied.

The first point at issue is the bearing of the experiment upon the relative tendency to repetition among men and women. Leaving the earlier comparison out of account, the number of different words is given in connection with the Wisconsin results:

Wisc. Univ. Men. Wisc. Univ. Women. Wellesley Women (1896.) I375 $1123 \quad 1306$

The comparison of the percentage of different words $(52 \%)$ in the Wellesley lists, with that in the lists of the Wisconsin men $(55 \%)$, seems to me an insufficient basis for the conclusion that 'there is less variety among women than among men,' especially as it is possible that the slightly greater rapidity with which the Wellesley lists were written may have reduced the number.

The comparison of ' unique words' or words appearing but once, also shows a greater originality on the part of the Wellesley women. Among our 2,500 words, there are 868 which occur but once, while the 
Wisconsin men's lists include 746, and those of the Wisconsin women only 520. Dr. Jastrow (who has kindly read this paper in manuscript) regards this large number of unique words as 'suspicious,' adding that " it suggests that a very few students added an unusual number of different and unique words." Our records, however, do not confirm this hypothesis, for they show that the lists which contain an unusually small number of 'unique' words approximately balance the particularly full records. Dr. Jastrow adds that he should have rejected a record containing a long list of prepositions evidently following upon the chance occurrence of the first of them, "as the associations are purely verbal and artificial. What we want," he adds, "is one hundred different ideas." I am sorry that this suggestion came too late to be followed, yet I think that it proposes an unattainable standard, since it seems to me impossible to distinguish, in such lists, between 'verbal' and 'idea' associations.

The view that some other influence than that of sex may account for the difference in 'repetition' between the Wisconsin men and the women, seems to me to be further strengthened by the results of certain experiments in controlled association, first performed by Dr. Jastrow ${ }^{1}$ and recently repeated at Wellesley. Ten concrete monosyllabic nouns were successively shown and the subjects were directed, after each, to write ' the first word suggested.' Dr. Jastrow finds that in this case "the tendency to repeat is not stronger in women than in men," and our Wellesley results from 42 records (a number equalling that of the Wisconsin men and greater than that of the Wisconsin women) shows an even lower tendency to repetition; 50\% as compared with $65 \%$. Yet if there is really among women a greater tendency to repetition, it should show itself in every form of unreflective and immediate thought.

The Wellesley results distinctly, therefore, oppose the generalization concerning the tendency of women to repeat each other. On the other hand, they seem to confirm several conclusions concerning prominent objects of imagination. The full classification is the following and includes the earlier Wellesley records, for purposes of comparison:

'Educational Review;" II. p. $44^{8}$. 
Table of Different Words.

\begin{tabular}{|c|c|c|c|c|}
\hline & 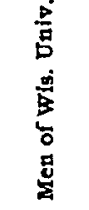 & 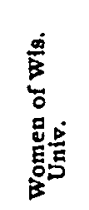 & 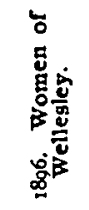 & 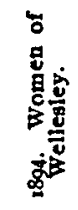 \\
\hline I. Animal Kingdom, . . . . . . . & 254 & 178 & 146 & 223 \\
\hline 2. Wearing Apparel and Fabrics, .... & 129 & 224 & 97 & 96 \\
\hline 3. Proper Names, $\ldots \ldots \ldots$ & 194 & 153 & $8 \mathrm{i}$ & 141 \\
\hline 4. Verbs, $\ldots \ldots$ & 197 & 134 & 279 & $\mathrm{II}_{4}$ \\
\hline 5. Implements and Utensils, & 169 & 121 & 139 & $13^{2}$ \\
\hline 6. Interior Furnishings, . . . . & 89 & 190 & 212 & 84 \\
\hline 7. Adjectives, . . . . . & I 77 & 102 & 300 & 234 \\
\hline 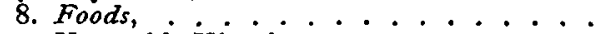 & 53 & 179 & 88 & 56 \\
\hline 9. Vegetable Kingdom, . . & $12 \mathrm{I}$ & 110 & 101 & $9 \mathrm{I}$ \\
\hline 10. Abstract Terms, . . . . . & 131 & 97 & IOI & 280 \\
\hline 11. Buildings and Building Materials, . . . & 105 & II7 & 86 & 106 \\
\hline 12. Parts of Body, . . . . . . & IOI & 105 & 66 & 34 \\
\hline 13. Miscellaneous, . . . . . . . . & $9 \mathrm{I}$ & 97 & 123 & 162 \\
\hline 14. Geographical and Landscape Features, . & 97 & 80 & 70 & $x_{42}$ \\
\hline 15. Mineral Kingdom, $\cdot \cdot^{-} \cdot \cdots$ & 74 & 96 & 30 & 54 \\
\hline x6. Meteorological and Astronomical, . . & 85 & 76 & 109 & 26 \\
\hline I7. Stationery, $\ldots . . \ldots$ & 60 & 86 & 69 & 26 \\
\hline 18. Occupations and Callings, $\ldots \ldots$ & 71 & 47 & 24 & 33 \\
\hline 19. Conveyances, . . . . . . . & 62 & 52 & 19 & 79 \\
\hline 2o. Educational, . . . . . . & 34 & 76 & 102 & 167 \\
\hline 21. Other Parts of Speech, . . . . & 96 & 5 & 164 & $4^{x}$ \\
\hline 22. Arts, . . . . . . . . & 33 & 61 & 17 & 44 \\
\hline 23. Amusements, . . . . & 30 & 53 & 17 & 102 \\
\hline 24. Mercantile Terms, . . . . . . & 30 & 29 & 18 & 15 \\
\hline 25. Kinship, . . . . . . . & I7 & 32 & 42 & 18 \\
\hline 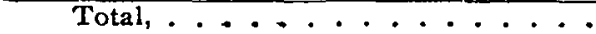 & 2,500 & 2,500 & 2,500 & 2,500 \\
\hline
\end{tabular}

The figures of the two Wellesley experiments certainly differ at several points and thus bear out the view of Dr. Jastrow and of Mr. Havelock Ellis, that the lack of extreme rapidity in writing brought about the divergence of the earlier Wellesley results. This difference is very marked in the case of abstract terms which fall far below the figure of the first Wellesley results, though it is proper to add that in the fear of overcrowding the class and in the effort to follow exactly Dr. Jastrow's principle of division, many words which seemed to me genuine abstracts were omitted. The prominence of the class of interior furnishings is the case of most marked agreement with the Wisconsin results. Foods also appear two-fifths more often than in the men's lists, yet only half as often as in the Wisconsin women's lists. On the other hand ' wearing apparel and fabrics,' supposedly objects of ardent feminine interest are named one-fourth less often than in the 
men's lists; and 'arts' and 'amusements' fall below any previous level. The results thus confirm some, yet not all, the conclusions concerning differences in predominant objects of interest. They certainly need to be supplemented by other figures since, as Dr. Jastrow remarks, "in dealing with such small groups . . . large room must be allowed for accidental variation."

It still seems to me, however, that such investigation is likely to lead to the confusion of two distinct problems and that one of these is practically insoluble. A statistical study may truly, if sufficiently extended, establish characteristic differences in the interests of men and women, and all Dr. Jastrow's conclusions may in fact be interpreted in this way. Mr. Havelock Ellis, however, and Dr. Jastrow, perhaps, by the expression 'masculine and feminine mental traits,' attempt a distinction between masculine and feminine intellect per se, and this seems to me futile and impossible, because of our entire inability to eliminate the effect of environment. Now the differences in the training and tradition of men and women begin with the earliest months of infancy and continue through life. Most of the preferences which have been substantiated by both experimenters, for instance that of women for the surroundings of a home, are obviously cultivated interests. On the other hand, the only characteristics discussed on which the supposed fundamental distinction of masculine and feminine intellect could be based, are the prevalence of abstract terms and the tendency to repetition. On the former score, the figures certainly show more abstract terms on the men's lists, yet the whole number of words considered seems to me too small to warrant fixed conclusions. The number of 'repeated words' is however large enough to form a fair basis for preliminary conclusions, yet just at this point the Wellesley figures definitely oppose those of the Wisconsin experiment. The question of the essential difference between masculine and feminine mind seems to me, therefore, untouched by such an investigation.

\section{Weilestey College.}

\section{Mary Whiton Calkins.}

Miss Calkins has submitted the above notes to me before publication; it may, therefore, be appropriate for me to record my conviction that the main points at issue, the relative variability of men and women and the differences in their interests, still seem to me to suggest the solution originally outlined in my paper. On re-reading that paper, I can find no suggestion of a claim for a wider application of the generalizations reached than that of the special results presented. The 